\title{
Resistance to Red Rot Disease (Colletotrichum falcatum) Varies among Different Germplasm Sources of Sugarcane
}

\author{
Hafiz Muhammad Walayat Ali Khan ${ }^{1}$, Mahmood-Ul-Hassan ${ }^{1 *}$, Muhammad Akhlaq Mudassir ${ }^{1}$, Muhammad Shahzad \\ Afzal $^{1}$, Muhammad Yasin ${ }^{1}$, Muhammad Farooq Ahmad ${ }^{2}$ and Muhammad Munir ${ }^{3}$ \\ ${ }^{1}$ Sugarcane Research Institute, Ayub Agricultural Research Institute, Faisalabad 38850, Pakistan \\ ${ }^{2}$ Sugarcane Breeding Sub-Station, Murree, Rawalpindi, Pakistan \\ ${ }^{3}$ Entomological Research Institute, Ayub Agricultural Research Institute, Faisalabad 38850, Pakistan \\ For correspondence: muh.agr@gmail.com \\ Received 16 July 2020; Accepted 02 November 2020; Published 10 January 2021
}

\begin{abstract}
Resistance of sugarcane varieties to red rot disease is essential for their successful commercial cultivation in Pakistan. Evaluation of sugarcane germplasm for red rot resistance is a basic component of the varietal development system in Punjab. The studies on varietal screening against red rot disease of exotic sugarcane germplasm were conducted at the research farm of the Sugarcane Research Institute, Faisalabad from 2008-2009 to 2010-2011. The screening test was carried out at different varietal development stages including sugarcane nursery-2, nursery-3, semi-final varietal trial, final varietal trial and National Uniform Yield Trial by using plug method of inoculation. In three years, 724 sugarcane genotypes were examined in screening test against red rot disease, which were developed from germplasm (fuzz), imported from different sugarcane breeding organizations of the world. Fuzz is a true seed of sugarcane used to develop new sugarcane variety(ies) through repeated selection in any varietal development program. The results of three years experimentation revealed that 425 genotypes were resistant, 141 moderately resistant, 48 moderately susceptible and 110 susceptible to red rot disease. It was also concluded that sugarcane germplasm belongs to the USA, proved to be superior for resistance to red rot disease with $91 \%$ genotypes followed by Brazil and Australia with 86 and $68 \%$ genotypes, respectively, which were classified in resistant and moderately resistant category. (C) 2021 Friends Science Publishers
\end{abstract}

Keywords: Germplasm; Red rot disease; Resistance; Screening; Sources; Sugarcane

\section{Introduction}

Sugarcane is one of the major cash crops of Pakistan that contributes considerably to economy of the country and global agricultural production. It plays a vital role in employing directly about one million people of the nation being $2^{\text {nd }}$ largest sugar industry after textile sector. More than 4 million people are also engaged indirectly in growing and marketing of sugarcane, and its associated production sectors like beverages, alcohol, paper, animal feeds and organic fertilizer etc. Pakistan is ranked $5^{\text {th }}$ in sugarcane cultivated area and total production globally, producing about 6 million tons of sugar annually (FAO 2017). However, the average yield of sugarcane is lower than the main sugar producing nations. The unavailability of high quality local fuzz (true seed), changing climatic extremes and incidence of new weeds, insects \& diseases are considered to be major agricultural factors that are adversely affecting national sugarcane yield.

Like other crops, sugarcane is also infected by several plant diseases. Among sugarcane diseases (fungal, bacterial, viral and phytoplasmal) fungal diseases are most important on the international level (Bharti et al. 2012). Out of these, red rot is the most destructive disease, which is widely spread and has been reported in 68 sugarcane growing countries of the world (Bharti et al. 2012). In India, the epidemic of the disease occurred in 1895-1901 and in subsequent years, several major outbreaks have been observed on regular basis in the sugarcane growing areas of the country (Satyavir 2003). In Tamil Nadu, India, the sugar industry faced worst crisis due to the red rot menace during 1986-2002 (Viswanathan and Sundar 2002). In Pakistan, sugarcane growing areas of central Punjab and some of the northern side of the province is hotspot for red rot incidence due to favorable soil and climatic conditions. Earlier studies, conducted by Agnihotri et al. (1979) and Khan et al. (2011), reported that red rot is a seed born disease and is favored by warm and humid weather conditions accomplished with high rain, flooding and water logging. Sharma and Tamta (2015) reported that favorable conditions for the development of red rot disease included mean temperature ranging from 29.1 to $31^{\circ} \mathrm{C}, \mathrm{pH}$ 5-6 and high atmospheric humidity (90\%), waterlogged conditions of soil, continuous cultivation of

To cite this paper: Khan HMWA, Mahmood-Ul-Hassan, MA Mudassir, MS Afzal, M Yasin, MF Ahmad, M Munir (2021). Resistance to red rot disease (Colletotrichum falcatum) varies among different germplasm sources of sugarcane. Intl J Agric Biol 25:381-387 
same variety in field and presence of susceptible varieties in surroundings. Viswanathan et al. (2020) also reported a vital role of weather factors, particularly rainfall and temperature in the development of red rot disease and its severity. This disease infects plants by entering spores or esco-spores of pathogen through any sort of injury made by insect/borers attack and natural growth crakes. Red rot pathogen caused reduction in carbohydrates indents of diseased canes especially in susceptible varieties (Agnihotri and Madan 1989). It causes considerable loss by reducing crop germination up to $73 \%$ in spring planted crop while 19 to $56 \%$ germination loss in autumn crop (Singh and Singh 1994). Yield loss in sugarcane was reported from 34.6 to $73.7 \%$ in plant crop and up to $100 \%$ in ratoon (Pliansinchai et al. 1994) and $74.5 \%$ reduction in sugar recovery (Ahmad et al. 1986). These losses in cane and sugar quantity and quality are greatly dependent upon weather conditions, varieties and disease strains (Ghazanfar and Kamran 2016).

Different methods are involved in integrated management of disease like cultural and chemical, which are found to be helpful in reducing the incidence of red rot. However, in practice, their role is supplementary to manage the disease especially in case of systemic infection. In view of all these limitations, the most effective and economical strategy is the development and cultivation of resistant variety to overcome the disease problem (Mohanraj et al. 2012). There are many examples of sugarcane varieties which were resistant at the time of release but they have become susceptible when brought into general cultivation. This is due to the creation of new races of red rot disease that cause the breakdown of varietal resistance. The development of new races may be due to mutation, hetrokayriosis or change in climatic conditions. Newly released cultivars are subjected to red rot almost as soon as they become popular due to frequent emergence of new variants of red rot pathogen (Malathi et al. 2013).

As red rot incidence in sugarcane varieties varies greatly depending upon variety and locality, thus the disease is responsible for the failure of many popular varieties in different countries (Satyavir 2003). The isolates of disease are differentiated on the basis of morphology, physiology and host reaction parameters (Alvi et al. 2008). Kumar et al. (2011) demonstrated the difference in genetic makeup of resistant and susceptible genotypes of sugarcane regarding the reaction to red rot using modern amplified polymorphic DNA (RAPD) and universal rice primers (URP) molecular markers. Bharti et al. $(2014 \mathrm{a}, \mathrm{b})$ also found that races of red rot pathogen culturally, morphologically and pathogenically dissimilar with each other. Therefore, to study pathological and molecular variations in Colletotrichum falcatum, random amplification of polymorphic DNA (RAPD) primers and dendrogram analysis are important for race identification (Sakeena et al. 2013). Studies on pathogen flora during epidemics of red rot, revealed the appearance of new strains that are responsible for the failure of commercial varieties in sub-continent (Viswanathan 2010). New pathotypes of red rot have been reported from both tropical and subtropical regions of India, time to time (Viswanathan and Alexander 1997). The pathotypes from tropical areas are more virulent than sub-tropical areas (Viswanathan 2010). Major races of red rot used in the screening program were differentiated at morphological cultural, serological and pathogenicity levels (Viswanathan and Sundar 2002; Viswanathan et al. 2003). The isolates of a new race of red rot are named after the name of cultivar from which it was isolated. Likewise, isolate from cultivar COC-671 is named as cf.671.

This study was aimed at finding superior red rot resistant genotypes of sugarcane under the varietal development program of SRI, Faisalabad. As the new sugarcane germplasm varies for its red rot resistivity, so it can be preceded further in the program by expressing resistant reaction to red rot pathogen along with other biometric characteristics. Hence, to find out candidate red rot resistant sugarcane varieties that would be recommended for commercial cultivation in the province.

\section{Materials and Methods}

\section{Experimental location}

The study was carried out at the experimental area of the Sugarcane Research Institute (SRI), Ayub Agricultural Research Institute (AARI), Faisalabad, Pakistan for three consecutive crop seasons from 2008-2009 to 2010-2011.

\section{Research material}

Sugarcane genotypes (724) developed from fuzz, imported from USA (300), Australia (395) and Brazil (29) were tested for their disease resistance against red rot at different stages of varietal development program viz. nursery-2, nursery-3, semi-final varietal trial, final varietal trial and National Uniform Yield Trial (Table 1). The evaluation of varietal resistance to red rot is a basic component of sugarcane varietal development program of SRI, Faisalabad. A clone is promoted to the next stage on the basis of red rot resistance along with its superiority for other biometric traits.

\section{Screening methodology against red rot}

Experimentation on varietal screening was conducted under artificial inoculation conduction of red rot pathogen. The culture of red rot pathogen was prepared by growing on oatmeal agar media in the sugarcane pathology laboratory of the Institute. Ten-day cultures with sporulation were used for inoculation. Field inoculum was also established by growing infected seed of susceptible sugarcane variety Co-1148 in the field for development of disease nursery. Artificial inoculation of red rot pathogen was made during July. For this purpose, twenty-five clumps having at least two canes per clump of each clone were inoculated using plug method by injecting inoculum @ 20-25 spores per microscopic field 
or $10^{6}$ spores $\mathrm{mL}^{-1}$ of water (Viswanathan 2010). A borehole of about $0.5 \mathrm{~cm}$ diameter was made in the middle of cane stalk with the help of a cork borer (Grainger and Horne 1924) by removing plug of cane tissue (Mohanraj et al. 2012). Two drops of spore suspension of red rot pathogen (C. falcatum) were injected into the borehole and sealed tightly with sticking tape (Fig. 1).

\section{Assessment of disease reaction}

Data on incidence of disease was recorded by splitting inoculated cane stalk vertically after two months of inoculation. Assessment of varietal reaction was carried out with consideration of following symbolic points of disease and corresponding disease index on disease rating scale (09) (Srinivasan and Bhat 1961) as shown in Table 2.

\section{Symbolic points}

\section{Condition of top}

$$
\text { Green }(\mathrm{G})=0 \text { or Yellow } / \text { dry }(\mathrm{D})=1
$$

\section{Lesion width}

Lesion width of inoculated internodes is assigned score of 1 , 2 or 3 depending on the proportion of internodal tissue affected/discoloured.

\section{White spot}

A score of 1 or 2 is assigned according to whether the spots are restricted or progressed.

\section{Nodal transgression}

The number of nodes crossed above the inoculated internode and given score as:

i. If one node is crossed

ii. If two nodes are crossed

iii. If three or more are crossed (maximum)

\section{Statistical analysis}

The data recorded were undergone to Microsoft Excel-2016 to prepare graphs and other mathematical calculations.

\section{Results}

The sugarcane genotypes developed from fuzz belongs to three different international origins are differed for their resistance or susceptibility against red rot pathogen. The disease reaction of genotypes to red rot not only varied among germplasm sources but also at various stages of varietal development program as the resistivity increased with genotypes progressed to next phase. It was noticed that among 724 sugarcane genotypes, 425 examined resistant, 141 moderately resistant, 48 moderately susceptible and 110 susceptible to red rot in disease screening (Fig. 2).

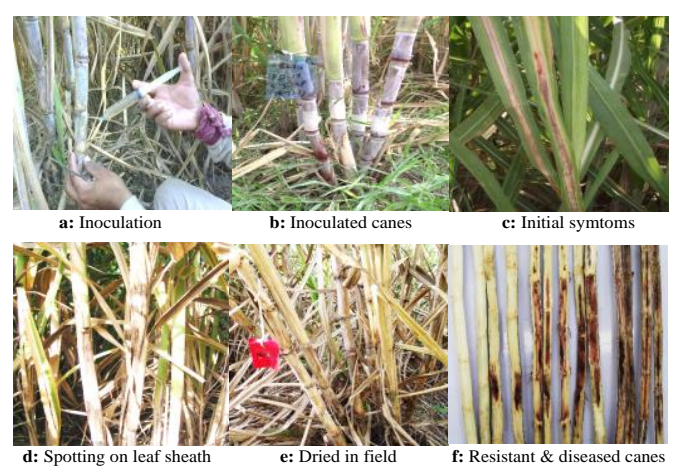

Fig. 1: Screening cycle of plug technique for testing sugarcane germplasm against red rot

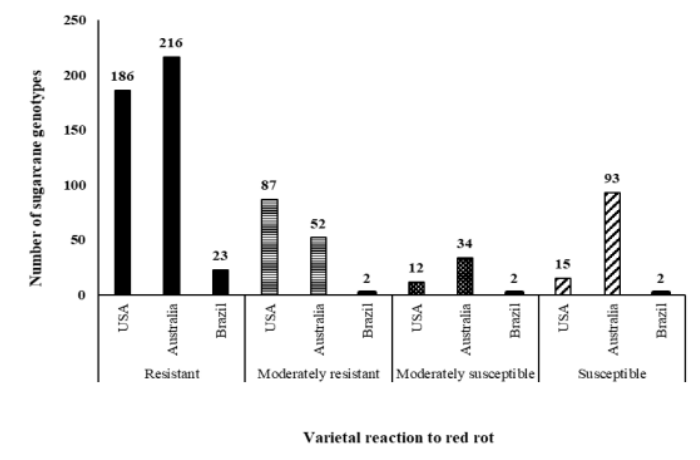

Fig. 2: Occurrence of red rot in 724 sugarcane germplasm of different origins

\section{Sugarcane nurseries (N-2 \& N-3)}

Nursery- 2 and nursery- 3 are third and fourth selection stages of sugarcane varietal development program. The details of perusal given in Table 3 reveals that during three years of study, 166 sugarcane genotypes belong to Sugarcane Field Station, Canal Point, Florida, USA was tested for red rot screening in sugarcane nurseries at preliminary stages. Among all, 109 clones showed resistant reaction, 47 moderately resistant, 04 moderately susceptible and 06 clones were found susceptible to red rot disease. Out of 368 sugarcane lines of Australian germplasm, 205 were ranked as resistant, 45 moderately resistant, 30 moderately susceptible and 88 susceptible to red rot. Brazilian sugarcane germplasm comprised of 22 clones, out of which 18 lines had resistance, 2 moderately resistance against red rot disease while 1 line each was found moderately susceptible and susceptible.

\section{Varietal trials (semi-final and final varietal trials)}

Being fifth and sixth testing stage of varietal development program, the superior sugarcane clones promoted from semifinal and final varietal trial on having red rot resistance and desired biometric traits are further put in the outfield or zonal varietal trials on farmers' field for testing their adaptability at wider level in all cane growing districts of the province. Data of three years presented in Table 3 depicted that from USA 
Khan et al. / Intl J Agric Biol, Vol 25, No 2, 2021

Table 1: Distribution of 724 sugarcane genotypes belong to different origins for their red rot resistivity screened from 2008-09 to 201011 at various selection stages

\begin{tabular}{|c|c|c|c|c|c|c|c|c|c|c|c|c|c|c|c|c|}
\hline \multirow{2}{*}{$\begin{array}{l}\text { Origin/ } \\
\text { Source }\end{array}$} & \multirow[t]{2}{*}{ Reaction } & \multicolumn{5}{|c|}{$2008-2009$} & \multicolumn{5}{|c|}{$2009-2010$} & \multicolumn{5}{|c|}{$2010-2011$} \\
\hline & & $\mathrm{N} 2$ & N3 & SFVT & FVT & NUYT & N2 & N3 & SFVT & FVT & NUYT & $\mathrm{N} 2$ & N3 & SFVT & FVT & NUYT \\
\hline \multirow{3}{*}{$\begin{array}{l}\text { USA } \\
(300)\end{array}$} & $\mathrm{R}$ & - & 39 & 12 & 16 & 4 & 70 & - & 14 & 9 & 4 & - & - & 5 & 9 & 4 \\
\hline & MR & 21 & 7 & 1 & 5 & 1 & 19 & - & 5 & 6 & 8 & - & - & 1 & 9 & 4 \\
\hline & S & - & 1 & - & 1 & 1 & 5 & - & 1 & 1 & 1 & - & - & 1 & 1 & 2 \\
\hline \multirow{4}{*}{$\begin{array}{l}\text { Australia } \\
(395)\end{array}$} & $\mathrm{R}$ & 106 & - & 2 & - & - & - & 39 & - & - & - & 37 & 23 & 9 & - & - \\
\hline & MR & - & - & - & - & - & - & 10 & - & 1 & - & 24 & 11 & 5 & 1 & - \\
\hline & MS & 10 & - & - & - & - & - & 4 & 1 & - & - & 11 & 5 & 3 & - & - \\
\hline & S & 32 & - & - & - & - & - & 16 & - & - & - & 37 & 3 & 5 & - & - \\
\hline \multirow{4}{*}{$\begin{array}{l}\text { Brazil } \\
(29)\end{array}$} & $\mathrm{R}$ & 10 & 8 & - & - & - & - & - & 2 & - & - & - & - & 1 & 2 & - \\
\hline & MR & 2 & - & - & - & - & - & - & - & - & - & - & - & - & - & - \\
\hline & MS & - & 1 & - & - & - & - & - & 1 & - & - & - & - & - & - & - \\
\hline & S & - & 1 & - & - & - & - & - & - & - & - & - & - & 1 & - & - \\
\hline
\end{tabular}

$N 2=$ Nursery-2; $N 3=$ Nursery-3; SFVT=Semi-final varietal trial $; F V T=$ Final varietal trial $; N U Y T=$ National uniform yield trial

Table 2: Screening criteria for sugarcane germplasm to determine red rot resistance

\begin{tabular}{ll}
\hline Reaction of sugarcane genotypes to red rot disease & Disease index (score) \\
\hline Resistant (R) & $0.0-2.0$ \\
Moderately resistant (MR) & $2.1-4.0$ \\
Moderately susceptible (MS) & $4.1-6.0$ \\
Susceptible (S) & $6.1-8.0$ \\
Highly susceptible (HS) & Above 8.0 \\
\hline
\end{tabular}

Table 3: Disease reaction of sugarcane germplasm to red rot pathogen

Disease Reaction Reaction Year $\quad$ Selection Stage Sugarcane genotypes tested with origin

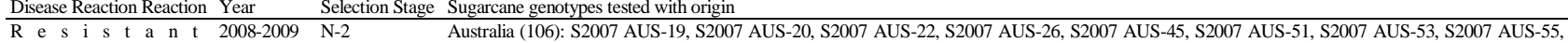
S2007 AUS-56, S2007 AUS-58, S2007 AUS-59, S2007 AUS-60, S2007 AUS-65, S2007 AUS-66, S2007 AUS-69, S2007 AUS-71, S2007 AUS-89, S2007 AUS-93, S2007 AUS-101, S2007 AUS-104, S2007 AUS-116, S2007 AUS-117, S2007 AUS-122, S2007 AUS-126, S2007 AUS-127, S2007 AUS-128, S2007 AUS-136, S2007 AUS-137, S2007 AUS-138, S2007 AUS-148, S2007 AUS-155, S2007 AUS-159, S2007 AUS-167, S2007 AUS169, S2007 AUS-170, S2007 AUS-172, S2007 AUS-173, S2007 AUS-174, S2007 AUS-192, S2007 AUS-196, S2007 AUS-201, S2007 AUS-204, S2007 AUS-210, S2007 AUS-212, S2007 AUS-216, S2007 AUS-2018, S2007 AUS-222, S2007 AUS-223, S2007 AUS-226, S2007 AUS-228, S2007 S2007 AUS-210, S2007 AUS-212, S2007 AUS-216, S2007 AUS-2018, S2007 AUS-222, S2007 AUS-223, S2007 AUS-226, S2007 AUS-228, S2007
AUS-231, S2007 AUS-236, S2007 AUS-237, S2007 AUS-244, S2007 AUS-246, S2007 AUS-247, S2007 AUS-253, S2007 AUS-254, S2007 AUS257, S2007 AUS-258, S2007 AUS-259, S2007 AUS-260, S2007 AUS-261, S2007 AUS-262, S2007 AUS-263, S2007 AUS-264, S2007 AUS-266, S2007 AUS-281, S2007 AUS-289, S2007 AUS-290, S2007 AUS-291, S2007 AUS-292, S2007 AUS-295, S2007 AUS-296, S2007 AUS-300, S2007 AUS-311, S2007 AUS-315, S2007 AUS-317, S2007 AUS-319, S2007 AUS-329, S2007 AUS-346, S2007 AUS-348, S2007 AUS-359, S2007 AUS360, S2007 AUS-362, S2007 AUS-377, S2007 AUS-384, S2007 AUS-393, S2007 AUS-400, S2007 AUS-408, S2007 AUS-417, S2007 AUS-420, S2007 AUS-421, S2007 AUS-422, S2007 AUS-424, S2007 AUS-442, S2007 AUS-450, S2007 AUS-458, S2007 AUS-460, S2007 AUS-461, S2007 AUS-462, S2007 AUS-463, S2007 AUS-464, S2007 AUS-468, S2007 AUS-470, S2007 AUS-476

Brazil (10):S2007 SP-486, S2007 SP-494, S2007 SP-507, S2007 SP-505, S2007 SP-506, S2007 SP-540, S2007 SP-543, S2007 SP-545, S2007 SP-546, S2007 SP-556

N-3 USA (39): S2006 US-245, S2006 US-283, S2006 US-285, S2006 US-300, S2006 US-315, S2006 US-320, S2006 US-321, S2006 US-334, S2006 US-380, S2006 US-395, S2006 US-421, S2006 US-420, S2006 US-424, S2006 US-425, S2006 US-434, S2006 US-439, S2006 US-443, S2006 US451, S2006 US-469, S2006 US-514, S2006 US-567, S2006 US-579, S2006 US-625, S2006 US-649, S2006 US-658, S2006 US-646, S2006 US-S2006 US-655, S2006 US-678, S2006 US-683, S2006 US-685, S2006 US-706, S2006 US-709, S2006 US-712, S2006 US-717, S2006 US-726, S2006 US728, S2006 US-739, S2006 US-832, S2006 US-904

Brazil(08):S2006 SP-17, S2006 SP-18, S2006 SP-22, S2006 SP-24, S2006 SP-25, S2006 SP-26, S2006 SP-27, S2006 SP-93, S2006 SP-137

SFVT USA (12): S2003 US-18, S2003 US-54, S2003 US-110, S2003 US-123, S2003 US-173, S2003 US-186, S2003 US-191, S2003 US-306, S2003 US345 , S2003 US-371, S2003 US-443, S2003 US-704 Australia (02):S2005 AUS-534, S2005 AUS-740

FVT USA (16):S2000 US-50, S2003 US-114, S2002 US-140, S2002 US-160, S2002 US-526, S2002 US-133, S2002 US-452, S2002 US-640, S2003 US127, S2003 US-212, S2003 US-394, S2003 US-623, S2003 US-624, S2003 US-633, S2002 US-637, S2003 US-694

$\begin{array}{ll}\text { NUYT } & \text { 127, S2003 US-212, S2003 US-394, S2003 US-623, S2003 US-624, S2003 }\end{array}$

2009-2010 N-2 USA(70): S2008 US-3, S2008 US-8, S2008 US-9, S2008 US-11, S2008 US-12, S2008 US-14, S2008 US-15, S2008 US-16, S2008 US-18, S2008 US20, S2008 US-27, S2008 US-36, S2008 US-43, S2008 US-44, S2008 US-47, S2008 US-49, S2008 US-52, S2008 US-53, S2008 US-54, S2008 US-55, S2008 US-56, S2008 US-58, S2008 US-59, S2008 US-60, S2008 US-63, S2008 US-64, S2008 US-65, S2008 US-73, S2008 US-76, S2008 US-77, S2008 US-79, S2008 US-80, S2008 US-85, S2008 US-87, S2008 US-92, S2008 US-94, S2008 US-96, S2008 US-99,S2008 US-100, S2008 US-123, S2008 US-101, S2008 US-104, S2008 US-110, S2008 US-114, S2008 US-116, S2008 US-119, S2008 US-126, S2008 US-127, S2008 US-128, S2008 US-129, S2008 US-130, S2008 US-132, S2008 US-133, S2008 US-134, S2008 US-143, S2008 US-144, S2008 US-145, S2008 US-146, S2008 US156, S2008 US-150, S2008 US-166, S2008 US-170, S2008 US-173, S2008 US-174, S2008 US-175, S2008 US-177, S2008 US-184, S2008 US-190, 156, S2008 US-150, S2008 US-166, S2008 US-17

N-3 Australia(39): S2007 AUS-19, S2007 AUS-26, S2007 AUS-53, S2007 AUS-55, S2007 AUS-56, S2007 AUS-58, S2007 AUS-59, S2007 AUS-66, S2007 AUS-73, S2007 AUS-99, S2007 AUS-104, S2007 AUS-137, S2007 AUS-138, S2007 AUS-155, S2007 AUS-159, S2007 AUS-162, S2007 AUS-167, S2007 AUS-170, S2007 AUS-215, S2007 AUS-218, S2007 AUS-222, S2007 AUS-226, S2007 AUS-231, S2007 AUS-259, S2007 AUS266, S2007 AUS-281, S2007 AUS-329, S2007 AUS-332, S2007 AUS-359, S2007 AUS-373, S2007 AUS-384, S2007 AUS-453, S2007 AUS-458, S2007 AUS-473, S2007 AUS-476, S2007 AUS-520, S2007 AUS-545, S2007 AUS-572, S2007 AUS-576

SFVT USA (14):S2004 US-306, S2004 US-371, S2006 US-255, S2006 US-315, S2006 US-321, S2006 US-334, S2006 US-420, S2006 US-425, S2006 US469, S2006 US-514, S2006 US-658, S2006 US-683, S2006 US-706, S2006 US-832 Brazil (02): S2006 SP-25, S2006 SP-93

FVT USA (09):S2000 US-50, S2003 US-13, S2003 US-410, S2003 US-623, S2003 US-633, S2003 US-637, S2003 US-694, S2003 US-704, S2003 US-718 NUYT USA (04): S2000 US-50, S2003 US-623, S2003 US-694, S2003 US-704

2010-2011 N-2 Australia (37):S2008AUS-129, S2008AUS-130, S2008-AUS-133, S2008-AUS-138, S2008-AUS-172, S2008-AUS-178, S2008-AUS-190, S2008AUS-195, S2009AUS-08, S2009AUS-19, S2009AUS-20, S2009AUS-23, S2009AUS-35, S2009AUS-37, S2009AUS-38, S2009AUS-45, S2009 AUS-52, S2009 AUS-79, S2009AUS-89, S2009AUS-92, S2009AUS-93, S2009AUS-94, S2009AUS-97, S2009AUS-98, S2009AUS-101, S2009AUS-102, S2009AUS-119,S2009AUS-145, S2009AUS-148, S2009AUS-164, S2009AUS-167, S2009AUS-168, S2009AUS-170, S2009AUS171, S2009AUS-182, S2009AUS-183, S2009AUS-184

Table 3: Continued 


\section{Resistance of Sugarcane Genotypes Against Red Rot Disease / Intl J Agric Biol, Vol 25, No 2, 2021}

Table 3: Continued

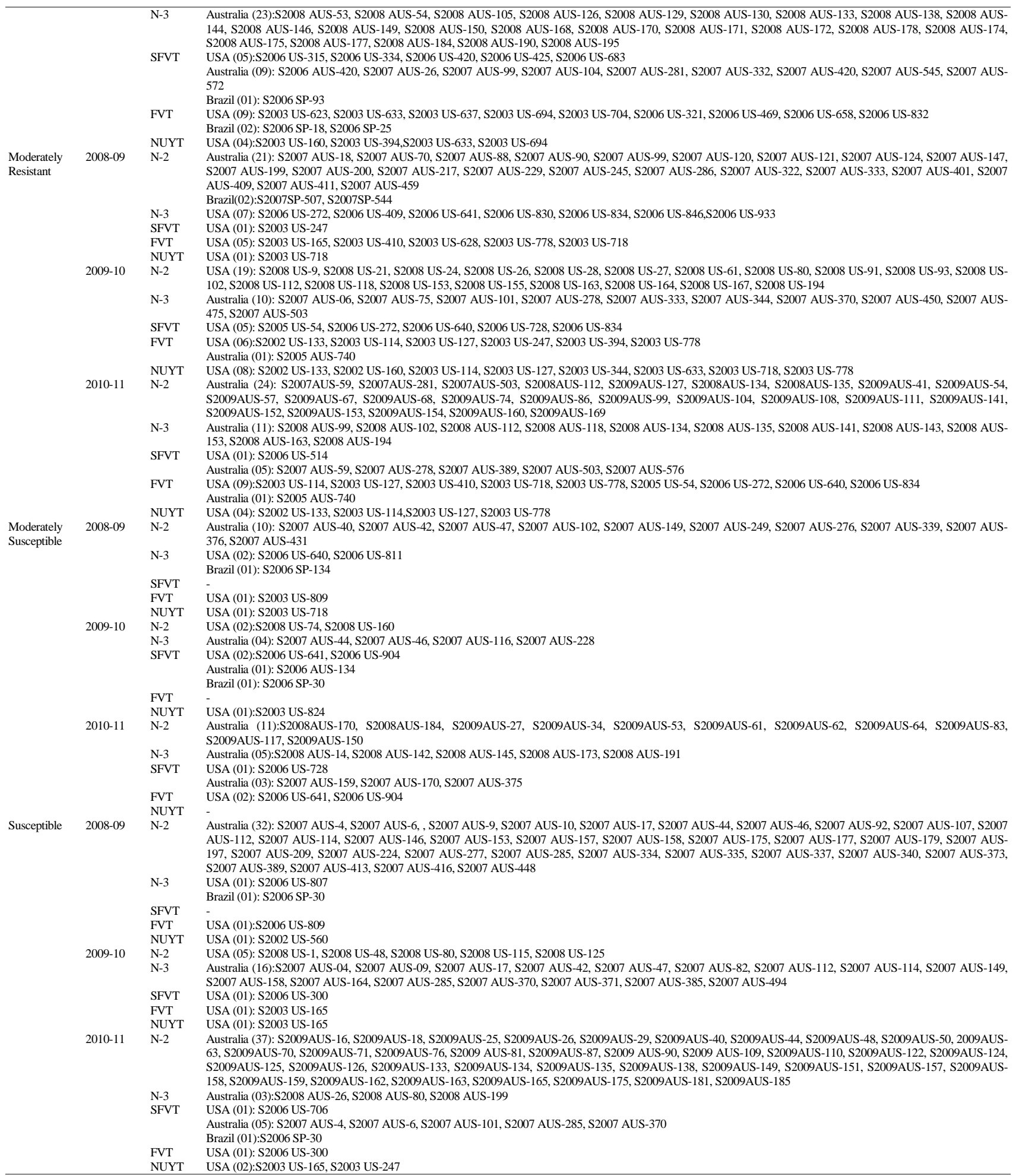

origin 103 sugarcane lines preceded under the experiment in both varietal trials. Out of which, 65 lines reacted as resistant, 27 moderately resistant, 6 moderately susceptible and 5 susceptible to red rot disease. Among 27 lines of sugarcane from Australian germplasm, 11 were found resistant, 7 moderately resistant and 4 moderately susceptible while 5 clones came under the susceptible category of disease reaction. Seven sugarcane lines of Brazilian origin were put 
under screening test at these stages, among which 5 expressed resistances, 1 moderately susceptible and 1 showed susceptible reaction to red rot disease.

\section{National uniform yield trails (NUYT)}

In this trial, 31 lines of sugarcane germplasm from USA were evaluated for their resistance to red rot pathogen (Table 3). Out of which, 12 lines were found resistant, 13 moderately resistant, 2 moderately susceptible and 4 susceptible to disease, whereas no Australian and Brazil origin sugarcane clone was tested for red rot screening under NUYT.

Overall, it was ascertained that the performance of sugarcane germplasm received from USA was better by having $91 \%$ resistant and moderately resistant genotypes to red rot. On the other hand, 86 and $68 \%$ genotypes of Brazilian and Australian germplasm, respectively, showed resistant and moderately resistant reaction to disease at different stages of varietal development program whereas $9 \%$ of sugarcane genotypes developed from the fuzz of USA, $14 \%$ of Brazil and $32 \%$ of Australia were assessed as moderately susceptible and susceptible to red rot disease.

\section{Discussion}

Sugarcane is a vegetatively propagated crop and no change occurs in the genetic makeup of a developed variety. However, failure of a cane variety would be due to the appearance of new races of diseases or insect pests. Red rot disease is a big threat to sugarcane crop in Pakistan. Pathogen of the disease is highly variable in nature, responsible for the breakdown of varietal resistance by creating virulent races or pathotypes (Sharma and Tamta 2015) and ultimately, it may result in exclusion of a commercial variety from the field. The resistance of sugarcane genotypes to red rot disease is a speciously complex phenomenon, characterized by morphological, physiological and environmental factors (Singh and Singh 1989). Moreover, genetic variation for red rot resistance depends on cross combinations made for breeding purposes. The exploitation of the variability in sugarcane crop due to its complex ploidy level and presence of high heterozygosity is a difficult process. Similar results were reported by (Sharma and Tamta 2020).

Disease susceptibility of sugarcane clone remained one of the key motivations to set up plant breeding programs in history. Several sugarcane industries were nearer to collapse due to disease epidemics but mostly recovered after the substitution of susceptible varieties with resistant ones, immune or tolerant varieties (Heinz 2015). Red rot occurs almost in most sugarcane growing countries after the replacement of noble canes by hybrids, however, it is the main problem in sub-tropical countries (Srinivasan and Alexander 1971). The SRI, Faisalabad has to depend mostly on exotic sources of sugarcane germplasm imported from different origins of the world due to limited local breeding program. The present investigations indicated that sugarcane accessions were resistant, moderately resistant, moderately susceptible and susceptible to red rot disease from all sources. Viswanathan et al. (2020) also reported that sugarcane varieties varying in disease resistance and disease buildup in the field with different pathogenic isolates are varying in their virulence. However, disease severity showed variation towards different origins and this level of variation could be due to genetic differences of Saccharum species used in the studies. This study also showed a comparatively higher level of red rot resistance in sugarcane germplasm of USA origin. The better resistance to red rot in USA germplasm is might be due to the selection of resistant parentage for crossing followed by an advanced breeding and varietal development program. Furthermore, similarity in latitude and climatic conditions of SRI, Faisalabad (Pakistan) and Sugarcane Field Station, Canal Point, Florida (USA) to some extent may be other factor, which favors the better adaptability of sugarcane germplasm of this origin in Punjab, Pakistan.

A genotypic-environment interaction in sugarcane was also observed while studying red rot resistance (MahmoodUl-Hassan et al. 2020; Viswanathan et al. 2020). The prevailing environmental factors can be extremely favorable for the development of red rot disease by adversely affecting cane plant in such a way that balance is turned in favour of red rot pathogen and cause serious loss to resistant varieties (Mcfarlane and Bailey 1996). For assessing the reaction of new sugarcane genotypes against red rot pathogen, artificial inoculation of standing stalks has proved to be a handy tool (Mcfarlane and Bailey 1996), due to which it is a routine procedure for all selection stages in the varietal development program of SRI, Faisalabad (Khan et al. 2011). In resistant clones, disease symptoms do not progress beyond inoculated internode of cane stalk.

Hence, continuous sugarcane breeding is inevitable for achieving red rot resistance and to avoid epiphytotic against red rot. During three consecutive years of study, it was observed that most genotypes exhibited different reactions to red rot assessment that might be due to their genetic build up, environmental variation and or change of pathotypes at the time of experimentation. Similar results were also reported by Hossain et al. (2017) for sugarcane genotypes. Thus, to confront this challenge, it requires uninterrupted breeding and selection of red rot resistant sugarcane genotypes acquiring good biometric traits. In this study, sugarcane genotypes assessed as resistant and moderately resistant to red rot and carrying good agronomic characteristics may be recommended for commercial cultivation and also would be utilized in future local breeding program to develop red rot resistant varieties (Hossain et al. 2017; Singh et al. 2017). Further studies are needed to be investigated for the screening of sugarcane varieties against red rot disease by using advanced breeding techniques and integrating it with genotypic environmental interaction in current modern era.

\section{Conclusion}

Results of this study confirmed the occurrence of red rot 
susceptibility to a certain level in current sugarcane germplasm. However, some superior clones with red rot resistance were also unveiled from current selection populations. Based on results, 425 accessions were identified as resistant and 141 moderately resistant against red rot pathogen, screened through plug method of inoculation. It was also divulged that sugarcane germplasm belongs to USA origin exhibited better resistivity to red rot as compared to Australian and Brazilian origin. The resistant and moderately resistant clones can be further utilized as candidate sugarcane varieties to proceed for commercial cultivation and or for local breeding program to produce future resistant sugarcane varieties against $C$. falcatum isolates.

\section{Author Contributions}

HMWAK planned and supervised execution of experiments, data analysis, interpretation of results and write up, MUH helped in executing experiments, analyzed data, interpreted the results, did illustrations and write up, MAM helped in experimentation and write up and MSA, MY, MFA and MM reviewed the write up and helped in providing logistic support.

\section{Acknowledgements}

The authors are highly thankful to the Sugarcane Research Institute-AARI, Faisalabad to provide the opportunity for carrying out this research. We also acknowledge all the field and supporting staff of SRI, Faisalabad for their valuable contribution in accomplishing this study.

\section{References}

Agnihotri VP, VK Madan (1989). Changes in carbohydrates and nucleicacids in sugarcane genotypes affected by Colletotrichum falcatum. Sugarcane 4:7-8

Agnihotri VP, TR Budhraja, K Singh (1979). Role of diseased setts and soil, and the annual recurrence of red rot in sugarcane. Intl Sugar J 82:263-265

Ahmad M, R Ali, S Fasihi (1986). Effect of different infection level of red rot of sugarcane on cane weight and juice quality. J Agric Res 24:129-131

Alvi AK, J Iqbal, AH Shah, YB Pan (2008). DNA based genetic variation for red rot resistance in sugarcane. Pak J Bot 40:1419-1425

Bharti YP, BK Singh, A Kumar, SP Singh, DN Shukla (2014a). Efficacy of fungicides and antibiotics against spore germination and sporulation of Colletotrichum falcatum Went, causing red rot disease of sugarcane in vitro and in vivo condition. Agriways 2:100-105

Bharti YP, A Kumar, DDK Sharma, SK Singh, DN Shukla (2014b). Morphological, physiological and pathological variation among isolates of Colletotrichum falcatum that cause red rot of sugarcane. Afr J Microbiol Res 8:1040-1049

Bharti YP, SK Vishwakarma, A Kumar, A Singh, ML Sharma, DN Shukla (2012). Physiological and pathological aspects of some new isolates of Colletotrichum falcatum causing red rot disease in Saccharum spp. complex. Acta Phytopathol Entomol Hung 47:35-50

FAO (2017). Food and Agriculture Organization of the United Nations. Available at: http://www.fao.org/faostat/en/\#data/QC (Accessed: 20 October 2019)

Ghazanfar MU, S Kamran (2016). Laboratory evaluation of different plant extracts against Colletotrichum falcatum causing red rot disease of sugarcane. J Environ Agric 1:68-73
Grainger K, AS Horne (1924). A method of inoculating the apple. Ann Bot 38:213-215

Heinz DJ (2015). Sugarcane improvement through breeding. In: Development in Crop Science, $11^{\text {th }}$ edn. Elsevier Science Publishing Company Inc., New York, USA

Hossain MI, MS Rahman, ME Reza, MO Khaiyam (2017). Screening of some sugarcane genotypes to wilt. Amer J Plant Biol 3:125-128

Khan HMW, AM Awais, W Raza, A Zia (2011). Identification of sugarcane lines with resistance to red rot. Pak J Phytopathol 23:98-102

Kumar N, J Tripta, S Styavir, RS Tilak (2011). Molecular and pathological characterization of Colletotrichum falcatuminfecting subtropical Indian sugarcane. J Phytopathol 159:260-267

Mahmood-Ul-Hassan, HMWA Khan, MA Mudassir, MS Afzal, M Yasin, W Muzaffar, MF Ahmed, N Ahmad (2020). Evaluation of new sugarcane genotypes for biometric traits, resistance to red rot and borers complex under agro-climatic conditions of Faisalabad, Pakistan. Intl J Agric Biol 23:623-629

Malathi P, R Viswanathan, AR Sundar, N Prakasam (2013). Keys to Identify pathogen variability in Colletotrichum falcatum Went causing red rot in sugarcane. Eur J Biol Sci 6:24-29

Mcfarlane SA, RA Bailey (1996). Screening of new sugarcane genotypes for resistance to red rot (Glomerella tucumanensis). Proc S Afr Sug Technol Assoc 70:7-10

Mohanraj D, P Padmanaban, R Visvanath (2012). Screening for red rot resistance in sugarcane. Fund Plant Sci Biotechnol 6:51-62

Pliansinchai U, T Sophanodon, P Chansukkho (1994). Loss assessment of sugarcane caused by red rot wilt in Sing Buri region, Thailand, pp:1-8. Research report Sugarcane. Raingan phonngan wichai pracham pi 2535, Oi. Suphan Buri 1994

Sakeena P, SK Vishwakarma, AK Tiwari, A Singh, A Kumar (2013). Pathological and molecular variation Colletotricum falcatumisolates causing red rot of sugarcane in the northwest zone of India. J Plant Prot Res 53:37-41

Satyavir S (2003). Red rot of sugarcane-Current scenario. Ind Phytopathol $56: 245-254$

Sharma R, S Tamta (2020). Genetic variation in sugarcane cultivars for red rot resistance revealed by resistant gene analog polymorphism markers. Vegetos 33:92-99

Sharma R, S Tamta (2015). A review on red rot: The "Cancer" of sugarcane. J Plant Pathol Micriobiol S1; Article 003

Singh A, P Singh, AK Tiwari, BL Sarma (2017). Assessment of sugarcane germplasm (Saccharum spp. complex) against red rot pathogen (Colletotrichum falcatum). Braz Arch Biol Technol 60:1-5

Singh K, RP Singh (1989). Red rot. In: Disease of Sugarcane: Major Diseases, pp:169-188. CRicaud, ET Egan, AG Gillaspie Jr, CG Hughes (Eds.). Elsevier, Amsterdam, The Netherlands

Singh N, GB Singh (1994). Effect of red rot incipient infections in sugarcane seed setts on germination. Ind J Sugar Technol 9:149-151

Srinivasan KV, KC Alexander (1971). Sources of resistance to red rot and smut in the species of Saccharum. Sugarcane Pathol Newsletter

Srinivasan KV, NR Bhat (1961). Red rot of sugarcane criteria for grading resistance. J Ind Bot Soc 40:566-577

Viswanathan R (2010). Plant Disease. In: Red Rot of Sugarcane, p:306. Anmol Publishers, New Delhi, India

Viswanathan R, AR Sundar (2002). Biotechnological approaches in management of sugarcane diseases. In: Sugarcane Crop Management, pp:324-350. Singh SB, GP Rao, S Eswaramoorthy (Eds.). Sci Tech Publishing LLC, Houston, Texas, USA

Viswanathan R, KC Alexander (1997). Management of sugarcane diseases. Ind J Sugar Technol 12:37-48

Viswanathan R, R Selvakumar, KM anivannan, R Nithyanantham, K Kaverinathan (2020). Behaviour of soil borne inoculum of Colletotrichum falcatum in causing red rot in sugarcane varieties with varying disease resistance. Sugar Technol 22:485-497

Viswanathan R, P Malathi, P Padmanaban (2003). Variation in sugarcane red rot pathogen Colletotrichum falcatum Went. In: Frontiers of Fungal Diversity in India, pp:639-667. Rao GP, C Manoharachari, DJ Bhat, RC Rajak, TN Lakhanpal (Eds.). International Book Distributing Co., Lucknow, India 